\title{
CHALLENGES IN THE REUSE AND UPGRADE OF PIER LUIGI NERVI'S STRUCTURES
}

\author{
R. CERAVOLO ${ }^{1}$, G. DE LUCIA ${ }^{1}$, E. LENTICCHIA ${ }^{1 *}$, G. MIRAGLIA ${ }^{1}$, \\ A. QUATTRONE ${ }^{1}$, F. TONDOLO ${ }^{1}$, E. MATTA ${ }^{2}$, G. SAMMARTANO ${ }^{2}$, A. SPANÒ ${ }^{2}$, \\ C. CHIORINO ${ }^{3}$, G. BRUSCHI ${ }^{4}, \mathrm{P} \mathrm{FACCIO}^{4}, \mathrm{~A} \mathrm{NANNI}^{5}$ \\ ${ }^{1}$ Department of Structural, Geotechnical and Building Engineering, \\ Politecnico di Torino, Turin, Italy. \\ e-mail: rosario.ceravolo@polito.it; giulia.delucia@polito.it; *erica.lenticchia@polito.it; \\ gaetano.miraglia@polito.it; antonino.quattrone@polito.it; francesco.tondolo@polito.it
}

2 Department of Architecture and Design Politecnico di Torino, Turin, Italy.

e-mail: emiliano.matta@polito.it; giulia.sammartano@polito.it; antonia.spano@polito.it

\author{
${ }^{3}$ Pier Luigi Nervi Project Association, Brussel, Belgium \\ e-mail: cristiana.chiorino@gmail.com \\ ${ }^{4}$ Dipartimento di Architettura, Costruzione e Conservazione \\ IUAV University of Venice, Venice, Italy. \\ e-mail: faccio@iuav.it \\ ${ }^{5}$ Civil, Architectural and Environmental Engineering Department \\ University of Miami, Miami, Florida, USA. \\ e-mail: nanni@miami.edu
}

Keywords: Historical Structure, $20^{\text {th }}$ century architectural heritage, Conservation Plan

\begin{abstract}
The paper presents the overall objectives of a funded research program for the development of a Conservation Plan (CP) for the two halls by Pier Luigi Nervi of the Turin Exhibition Center. The Turin Exhibition Center was conceived immediately after the Second World War to host primarily the annual Automobile Show, in connection with the presence in Turin of the FIAT motor company. The two main pavilions of the Center (Halls B and C) are outstanding examples of a pioneering use, of new advanced methods in reinforced concrete construction, combining innovative prefabrication procedures and the re-invention by Nervi of ferrocement, used to form extremely thin elements. The CP is expected to push and contribute to the preservation of the halls designed and built by Nervi, with special emphasis on structural and seismic vulnerability aspects, also due to concerns raised on the durability of concrete materials and technologies. Re-using these buildings entails the challenge to guarantee new extended service life to concrete structures built many decades ago and faces the need for a seismic assessment of these structures, in compliance to recent Italian standards.
\end{abstract}


R. Ceravolo, G. De Lucia, E. Lenticchia, G. Miraglia, A. Quattrone, F. Tondolo, E. Matta, G. Sammartano, A. Spanò, C. Chiorino, G. Bruschi, P. Faccio, A. Nanni

\section{INTRODUCTION}

The present work is part of a topical line regarding the analysis and structural diagnosis aimed at the conservation of $20^{\text {th }}$ century architectural heritage. A heritage of great importance which is however characterized by several problems, first of all the scarce recognition of their historical-documental value. In fact, the preservation of 20th century architecture has fully entered the wider disciplinary of conservation. However, in practice, this cultural awareness clashes with the difficulties involved in adapting recent buildings to current building regulations. Moreover, many of the characteristics of modern architecture - such as the use of advanced construction methods and materials and the development of new building types and forms - challenge traditional conservation approaches and raise new methodological issues. In fact, the assessment of the twentieth century architectures poses new problems in terms of material preservation, structural analysis and reuse [1] [2]. Addressing these challenges will require convergent contributions from experts of different fields. From the point of view of their seismic improvement, $20^{\text {th }}$ century buildings present specific issues, connected to the materials and techniques used for the construction, as well as to the complex and innovative spatiality; the continuous experimentations in all these areas have been among the characteristic features of architectural and engineering research of the past century [3]. For these reasons, in view of a restoration and re-functionalization of these buildings, it is a priority to carry out a careful evaluation of the structural performances, both as regards the level of safety in static conditions and from the point of view of seismic behavior. Experimental activities, including dynamic

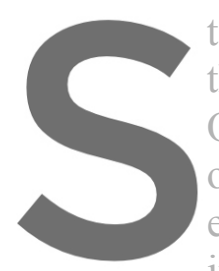
tests, are part of those op erations aimed at identifying the struc
the state of health of the structure and predicting the response
One of the reasons of the current abaddonment of the Turin
other Italian Nervi's buildings (e.g. Palazzo del Lavoro, Stadio
examples for guiding the renovation and/or reuse-projects of the in Italy. The contribution will address the issues regarding

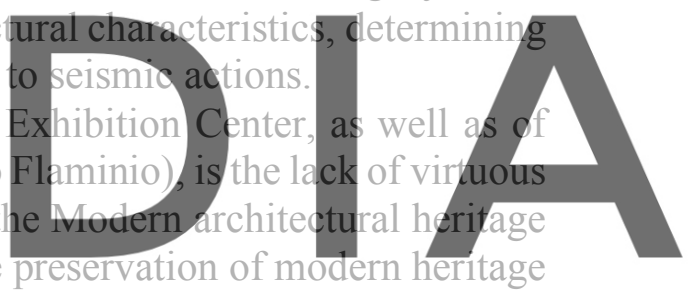
architecture as seen from the perspective of a country exposed to seismic risk. The paper

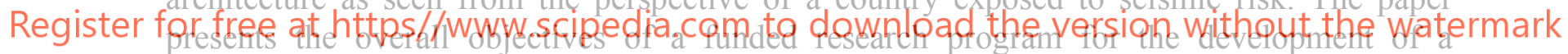
Conservation Plan (CP) for the two halls by Pier Luigi Nervi of the Turin Exhibition Center.

\section{THE CASE STUDY}

The monumental complex of Turin Exhibition Center represents a milestone in the history of modern engineering and architecture. The complex was designed and built between the 1948 and 1950 by Pier Luigi Nervi, one of the greatest and most inventive structural engineers of the $20^{\text {th }}$ century [4] [5], as a public space to host primarily the annual Automobile Show, in connection with the presence in Turin of the FIAT motor company. In the construction of both halls of Turin Exhibition Centre, Nervi used new construction procedures that he studied for some years before this project. In fact, he had already successfully used these procedures with his engineering firm Nervi and Bartoli, though on smaller experimental buildings, such as the small storehouse in the Magliana area in Rome (1946) [6], the wharf Conte Trossi in San Michele di Pagana (1947) and the ceiling of the pavilion at the Milan Fair (1947) [7]. Reference to this celebrated and iconic masterpiece, as one of the most skillful examples of structural art, is very frequent in the literature on contemporary architecture. This combined use of two 
R. Ceravolo, G. De Lucia, E. Lenticchia, G. Miraglia, A. Quattrone, F. Tondolo, E. Matta, G. Sammartano, A. Spanò, C. Chiorino, G. Bruschi, P. Faccio, A. Nanni

different technologies for the construction of large concrete shells, would become one of the distinctive trait of Nervi's work.
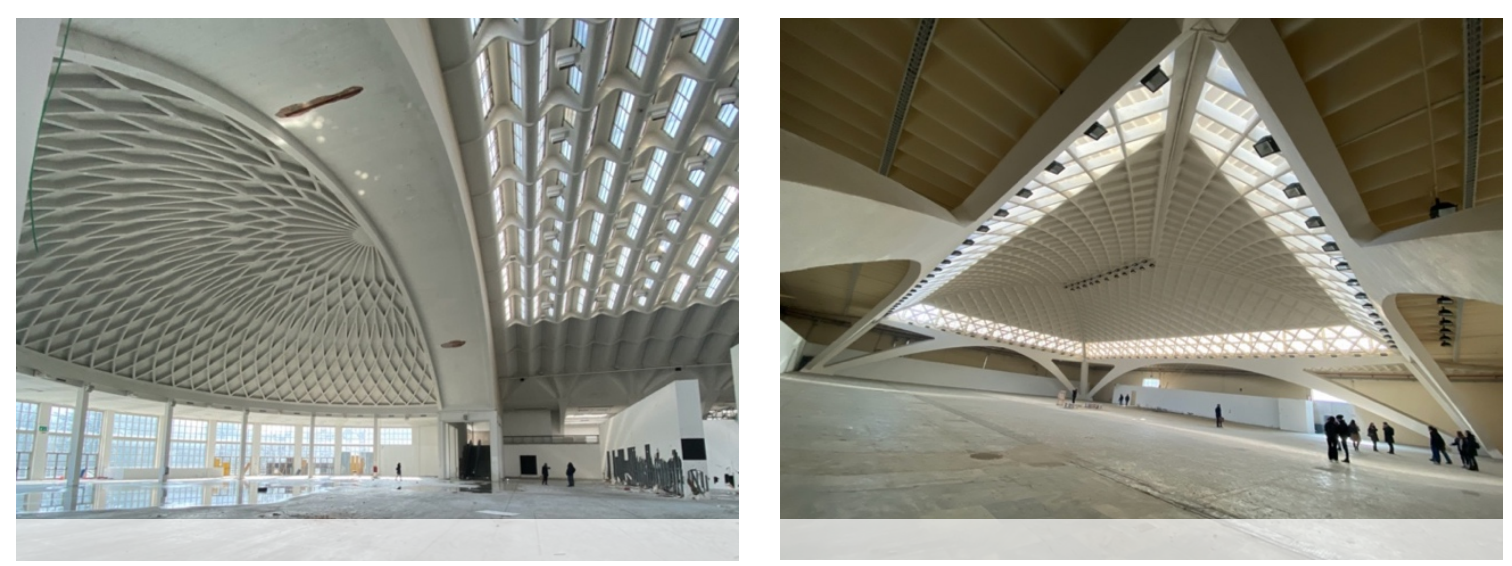

Figure 1: Turin Exhibition Center, Pavilions by Pier Luigi Nervi: Hall B (left and center) and Hall C (right).

The roofing systems, in particular, are outstanding examples of a pioneering use, at the intersection between inspiration and technique, of new advanced methods in reinforced concrete construction, combining extensive use of innovative prefabrication procedures and reinvention by Nervi of ferrocement, as an extremely malleable building material. As in the large majority of his works, Narvi was both the designer and, through its constructio
the builder of the Exhibition Center. In the fifties Nervi will be asked to design a secon
(Hall C) and to enlarge the Hall B. Figure 1 shows the interiors of the two halls buit
Shaped like a fascinating modern cathedral, Hall B (1947-1948) consists of an im
nave covered by a cyllndrical barrel vault, and an elegant apse with ribbed hemispher

For the realization of the arches of the vault, Nervi conceived wave-like prefabricated

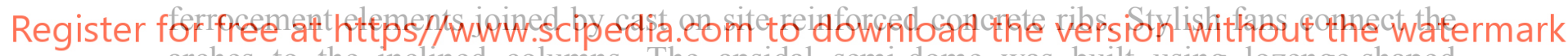
arches to the inclined columns. The apsidal semi-dome was built using lozenge-shaped ferrocement tiles connected by reinforced concrete cast in the lateral ribs and on their tops. Hall C (1950) is characterized by a captivating ribbed vault, constructed with the same system of ferrocement tiles and resting on four sculpturally shaped inclined arches. A clear proof on how significant the design and construction of both pavilions had been in the growth as a builder for Pier Luigi Nervi, is the fact that after the completion of both halls he immediately registered the patents of the solutions he employed during the construction site. In fact, Nervi registered various patents: patent no. 445781 in Rome on August $26^{\text {th }} 1948$, entitled "Ferrocement wave" and patent no. 465636 in on 19 May 1950, entitled "Building procedure for creating flat or curved load-resisting surfaces consisting of grids of reinforced concrete ribbing, possibly finished with connecting concrete slabs between the ribs" [8]. These patents would be adopted by Pier Luigi Nervi in the following decades until becoming a typical feature of the globally recognized Nervi's style [8] [9]. Moreover the experimentation of this new solutions was accompanied by the structural prefabrication, that Nervi already developed during the construction of a series of hangars for the Italian Air Force in the late 30s. It is important to note that Nervi's prefabrication did not concern factory-made standard construction elements. In fact, in each building he simply used prefab elements, made onsite. Nervi' s concept of 
R. Ceravolo, G. De Lucia, E. Lenticchia, G. Miraglia, A. Quattrone, F. Tondolo, E. Matta, G. Sammartano, A. Spanò, C. Chiorino, G. Bruschi, P. Faccio, A. Nanni

structural prefabrication meant that structures had to be broken down and each element had to be prepared on the ground (Figure 2). Every element had to be small enough and light enough to be lifted and easily assembled. Despite its misleading name (prefabrication) it is just a very old technique, in continuity with the tradition of stereometry.
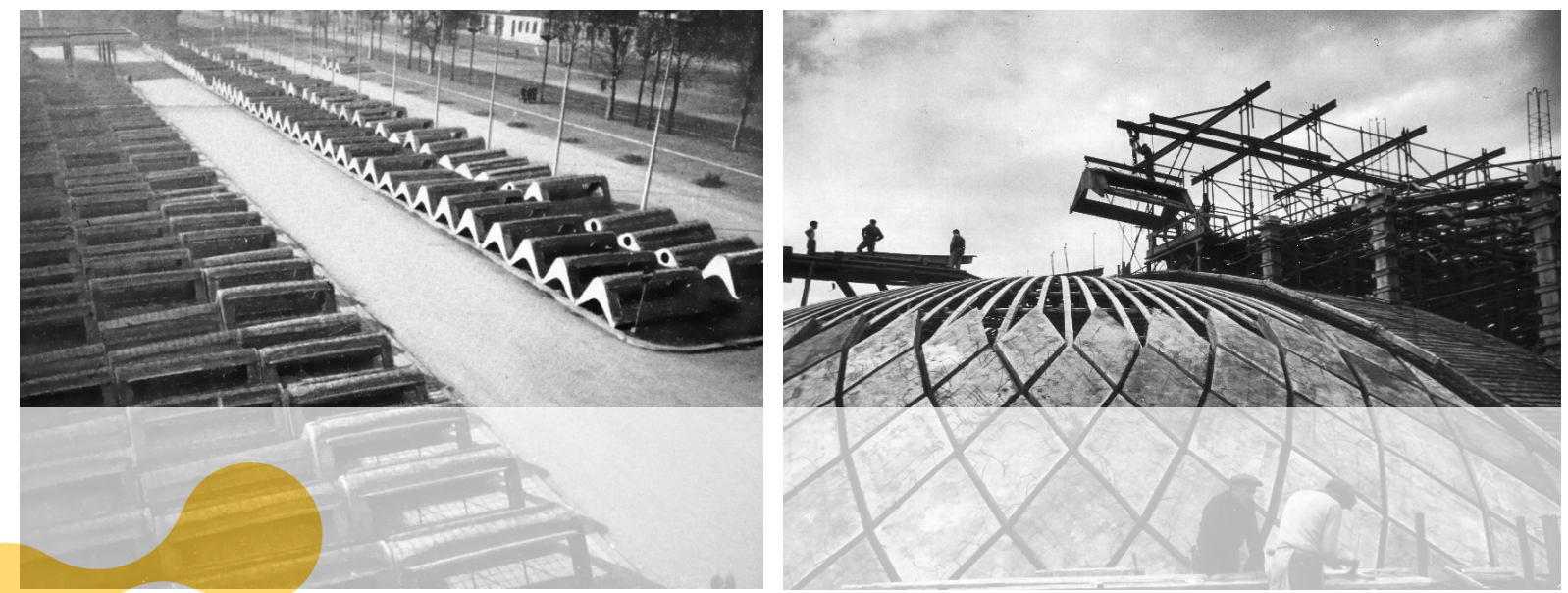

Figure 2: The onsite prefabrication procedure of the undulated ferrocement elements of Hall B and their positioning.
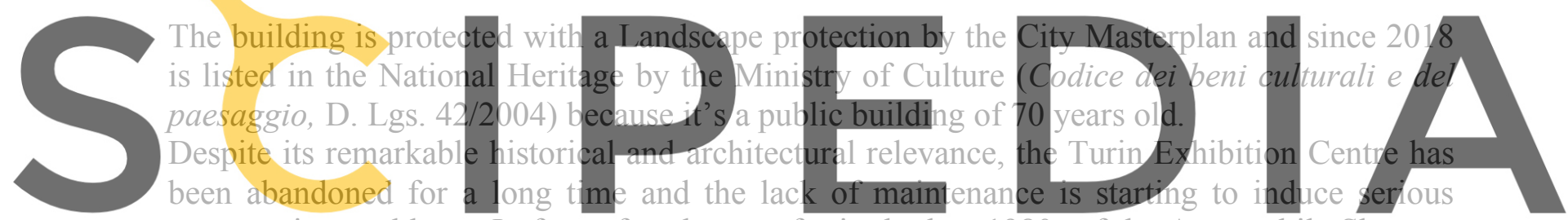

preservation problems. In fact, after the transfer in the late 1980s of the Automobile Show to

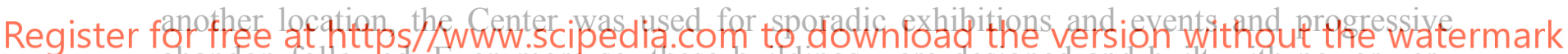
abandon followed. Even more so, these buildings were designed and built with no, or very

limited, seismic provisions, due to the lack of technical standards at the time. The CP will issue guidelines to reconcile structural requirements and conservation criteria.

\section{THE CONSERVATION PLAN}

The conservation of the architectural heritage of the modern movement is the latest and perhaps one of the most contentious frontiers in the field of architectural preservation. Long-standing prejudices and a persistent public lethargy often overcome objective analysis when Modern buildings are faced with demolition or disfiguring renovations [2] [3].

The first act in defining approaches related to the preservation of modern architecture is aimed at recognizing the object as a monument, document, or material testimony, having the value of civilization, which implies a conservative need or a slowing down of the processes of degradation. Criteria, principles and postulates of the modern restoration critically and scientifically understood (distinctiveness, minimal intervention, potential reversibility, respect for authenticity and ancient matter, physical-chemical compatibility of additions, recognition under the double aesthetic and historical requirement of the work) correspond to those developed for the now shared actions of restoration of monuments. These statements find a first 
R. Ceravolo, G. De Lucia, E. Lenticchia, G. Miraglia, A. Quattrone, F. Tondolo, E. Matta, G. Sammartano, A. Spanò, C. Chiorino, G. Bruschi, P. Faccio, A. Nanni

difficulty in the specific disciplines related to the conservation project, but will be overcome thanks to a holistic approach that focuses not on individual scientific contributions but the object as a central element of research in the unity of architecture and structure.

Also the ICOMOS20 groups states that "There is also some confusion about the basic principles of conservation that should be applied to twentieth-century sites and places" [10]. The difficulty, or even lack, of communication between architects and engineers has always been one of the main obstacles in the analysis and conservation of the architectural heritage. In fact international guidelines states that the conservation, reinforcement and restoration of the architectural heritage require a multidisciplinary approach. A typical example of interdisciplinary approach is the interaction that has to occur between historical research and structural diagnosis: historical research can discover particular phenomena involving structural behavior whilst historical questions may be answered by considering the structural behavior.

\subsection{Scope and challenges of the project}

More generally, the research project may be ascribed to the structural assessment and retrofit of $20^{\text {th }}$ century architectural heritage, characterized by a complex 3D structural design. The service life of civil and Cultural Heritage $(\mathrm{CH})$ concrete spatial structures is typically thought to range from 10 to 200 years, but in practice, the service environment plays a pivotal role in sustained durability. We address the challenge of monitoring, conserving and rehabilitating $20^{\text {th }}$ concrete $\mathrm{CH}$ because: concrete has become a $20^{\text {th }}$ century emblem; consequently, specific studies are needed that contribute to the successful reuse of modern concrete built heritage. More specifically, large architects and engineers structures are plagued retrofitting and/or radica to life, while respecting
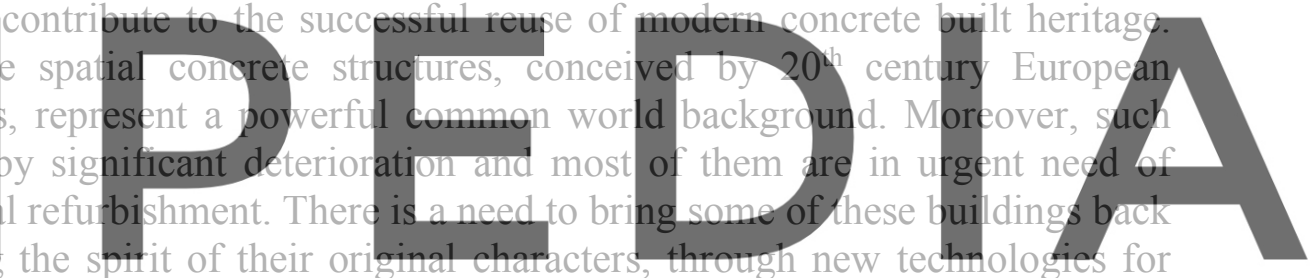

long-term conservation that can maintain an adequate level of structural and seismic

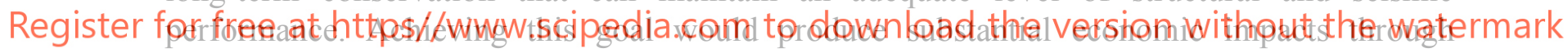
activities such as tourism, restoration, maintenance, and cultural industry

The scope of the research project is to develop a Conservation Plan for the two Halls designed and built by Pier Luigi Nervi in Turin Exhibition Center, with emphasis on structural and seismic issues. The project will be a mean to promote, support and guide the successive executive project of the building. An analytical investigation of Nervi's architecture, structures, materials and construction techniques will be supported by:

i) experimental tests on the building and its materials

ii) dynamic vibration-based tests

iii) historic and archival documents and direct observation

iv) accurate geometric survey through lidar and 3D restitution.

These activities will provide clear indications and recommendations for the conservation and restoration of the building's original characteristics, carried out by active experts of architectural heritage preservation. A special concern will be the correct modelling of the unconventional prefabricated ferrocement elements, a peculiarity of Nervi's vaulted structures which finds in these two halls a wide spectrum of constructive variants: in Hall B the wave-like elements of the undulated vault (interestingly interfering with the glass window panels); in Hall 
R. Ceravolo, G. De Lucia, E. Lenticchia, G. Miraglia, A. Quattrone, F. Tondolo, E. Matta, G. Sammartano, A. Spanò, C. Chiorino, G. Bruschi, P. Faccio, A. Nanni

$\mathrm{C}$ the diamond panels in the central portion of the vault and the undulated beams in the perimeter area. The unique features of these components make their mechanical behavior largely uncertain and their modelling a fundamental challenge to a reliable estimation of the present and future seismic safety of Turin Exhibition Center.

\section{WORKPLAN}

In order to overcome the difficulties in the diagnosis and the definition of a proper conservation strategy, the research propaedeutic to the Conservation Plan for the halls in Turin Exhibition Center will be centered different work streams. The various team will work together in order to carry out this main objectives:

1. Historical analysis of the building, investigating its design and construction process, with a particular focus on its technological features and characteristics.

2. Moreover a 3D dense clouds modelling derived from 3D sensing technologies (integrated and fused image and range based methods) will be produced;

3. Structural analysis of the building, considering the construction techniques and materials. Vibration-based dynamic tests will be carried out to investigate the global behavior and the health state of the two main halls and to define guidelines for possible interventions;

4. Analysis of the materials and their durability by means of experimental investigations
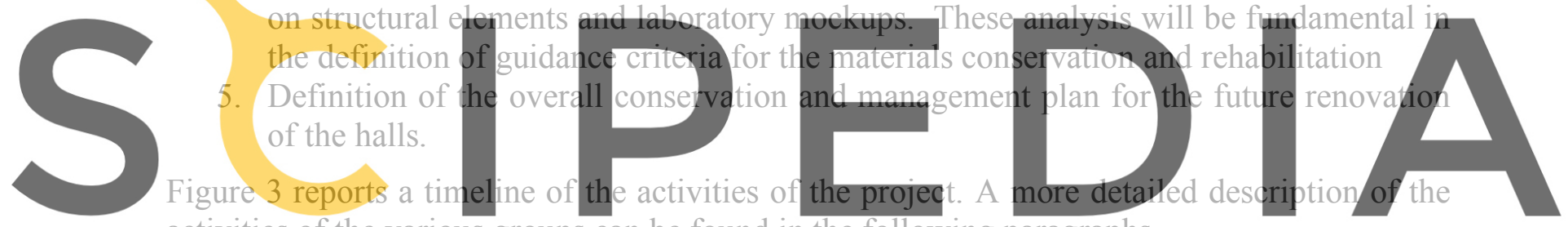

activities of the various groups can be found in the following paragraphs.

Register for free at https//www.scipedia.com to download the version without the watermark

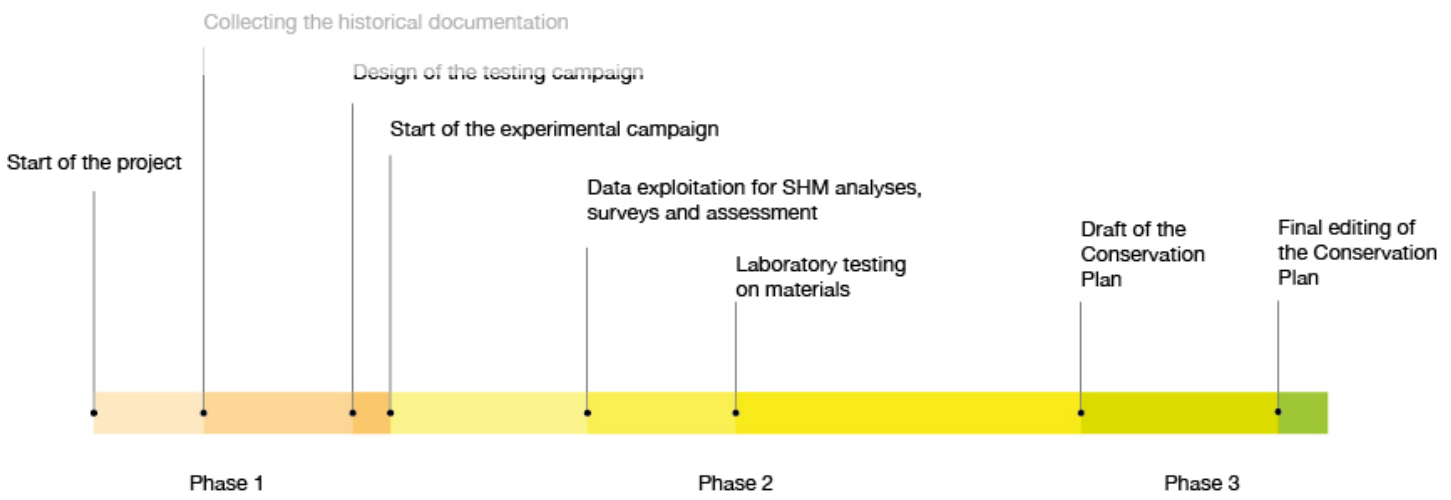

Figure 3: timeline of the project activities.

\subsection{Structural Health Monitoring and Seismic assessment of the building}

The first work stream is responsible for vibration-based tests and dynamic analysis in order to evaluate the response of the building to earthquakes and perform a seismic assessment of the 
R. Ceravolo, G. De Lucia, E. Lenticchia, G. Miraglia, A. Quattrone, F. Tondolo, E. Matta, G. Sammartano, A. Spanò, C. Chiorino, G. Bruschi, P. Faccio, A. Nanni

two Halls of the building. One of the main objective of this unit is the diagnosis of the health state of the halls. It involves a multi-scale approach based on the integration of experimental investigations carried out on-site and in the laboratory. Indeed, the conservation and rehabilitation of heritage buildings can be successfully accomplished only if a correct diagnosis has been formulated. Vibration-based structural health monitoring techniques have now become an important tool for the preservation of either antique or modern architectural heritage [11]. Dynamic tests are particularly appreciated in this field because they are a non-destructive technique and provide information about the whole-body response of the structure and its overall structural integrity. Accordingly, these techniques can in turn be undertaken for: i) understanding the structural behavior of a building; ii) assessing the response to specific events, by measuring some sensitive parameters and comparing them to typical threshold values.; iii) assessing the efficacy of structural or seismic interventions. The investigations of the structures in the dynamic and seismic domain are particularly important for this kind of structures, especially because they were designed and built to withstand only the gravity loads, accordingly to the technical standards of the time. An in-depth analysis of both hall C and B was carried out through several numerical investigations aimed at investigating the dynamic and structural response of the structures. The objective of this phase was to highlight the main criticalities of the structure and to evaluate the best strategy for the experimental campaign. An investigation of Hall C is reported in [12], while the more complex Hall B was analyzed in different steps: a preliminary model is reported in [13] and was implemented by adding the adjacent Hall A, in order to take into account the influence of an annexed structure. In the case of Hall B, the main critical aspects are connected to the large number of structural elements that govern the dynamic
behavior of the structure. These macro-elements and their influence on the dynamic response
of the building were described in [13]. In particular, it was pointed out that the most critical
responses are those related to the undulated thin shell vault, the out-of-plane movements of the
tympanums, and the presence of the apse, which cause a complex and potential vuluerable interaction with the main body of the hall. Similarly to Hall C, in Hall B bending and shear

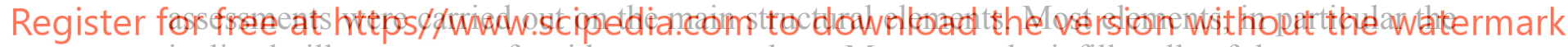
inclined pillars, are unsafe with respect to shear. Moreover, the infill walls of the tympanums are subjected to out-of-plane overturning (Figure 4).
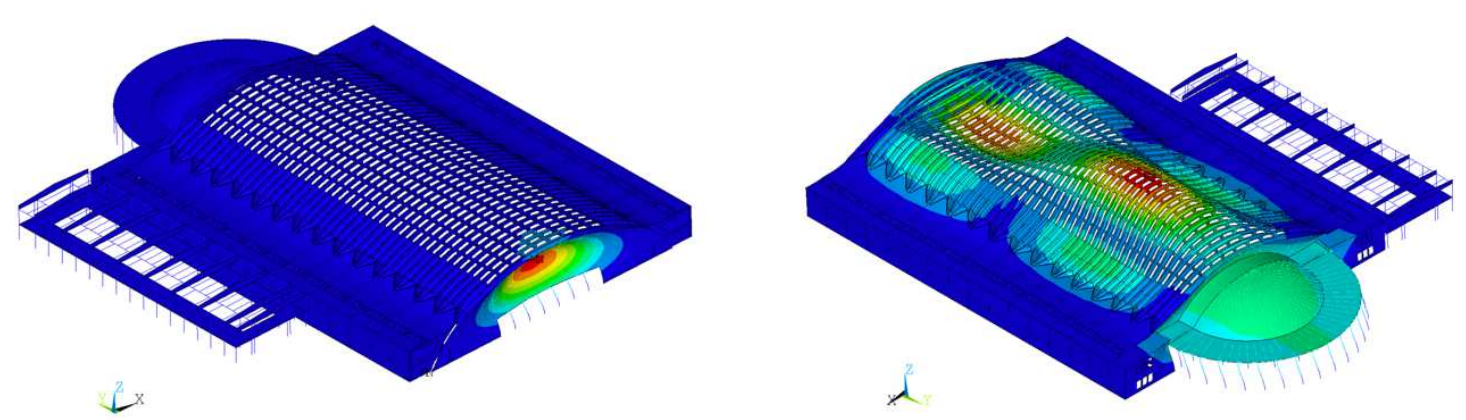

Figure 4: On the left, the out of plane movements of the front tympanum of Hall B; on the right, the interaction movements of the apse and the undulated vault.

The structure of Hall $\mathrm{C}$ consists of a vaulted roof supported by four inclined arches. It is completed by a perimetral slab of about 10 meters in length, sustained by a series of slim pillars and infill walls. The analysis started in [12] highlighted that the most vulnerable elements were 
R. Ceravolo, G. De Lucia, E. Lenticchia, G. Miraglia, A. Quattrone, F. Tondolo, E. Matta, G. Sammartano, A. Spanò, C. Chiorino, G. Bruschi, P. Faccio, A. Nanni

constituted by the dynamics of the inclined arches. These movements are amplified by their inertial mass, which is proportionally very high compared to the other elements of the hall, especially in comparison with the thin ribbed vault. Another critical aspect lies in the translation of the rigid cap of the roof with respect to the deformable contour ribs. Also due to the low ductility associated with these mechanisms, in case of moderate seismic events, the ribs may be affected by local interaction with the roof. Moreover, the main structural elements (arches, ferrocement elements, and pillars) were assessed with respect to bending and shear. In particular, results show that the arches are not verified with respect to shear loads. As a matter of fact, the shear reinforcement is weak if compared to current standards, as at the time designers were very confident about the resistance of concrete (Figure 5). Accordingly, the standards of the time only required a shear assessment for beam elements.

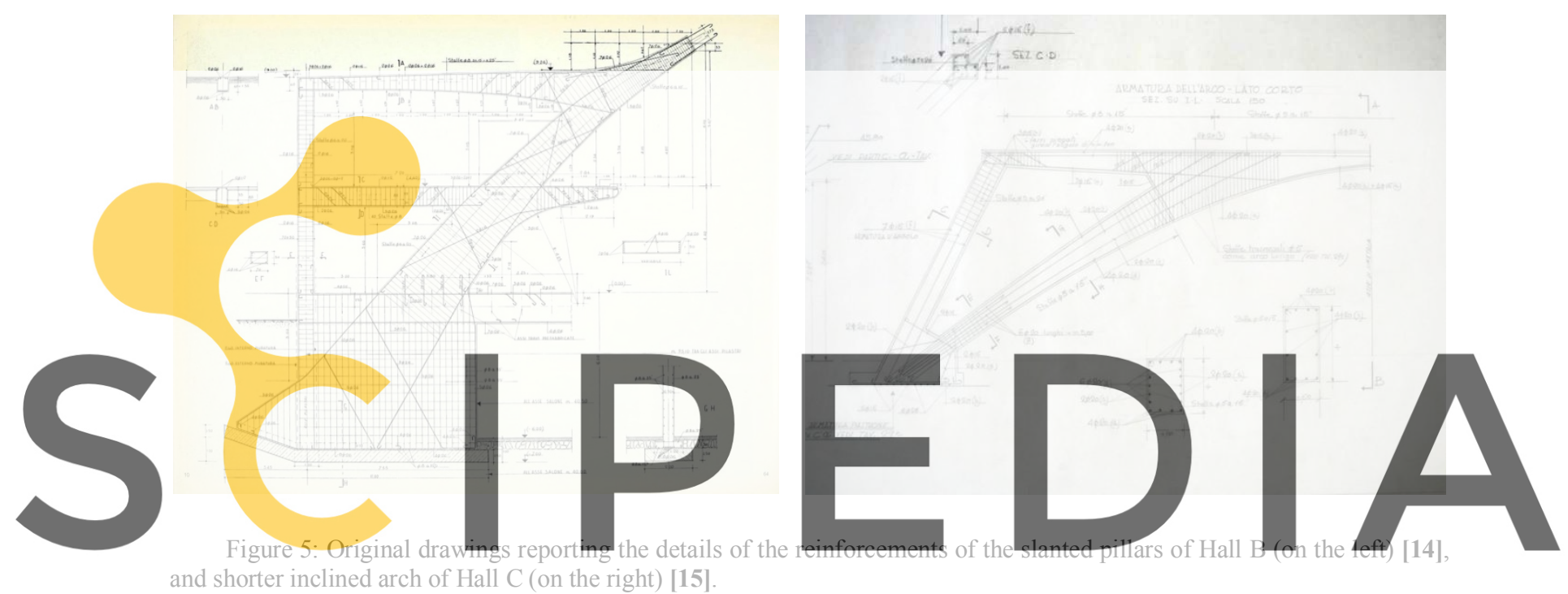

Register for free at. pttps//www.scipedia.com to download the version without the watermark

This research stream will carry out the investigation, diagnosis and testing of the materials, by means of on-site inspections, and experimental investigations on materials and mockups on the ferrocement elements. The characterization of the structural materials employed in Hall B and $\mathrm{C}$ will be used to reproduce, with the help of the documentation of the construction procedures used by Pier Luigi Nervi (e.g. cement type and content, aggregate dimension, etc.), laboratory mockups to be subjected to an accelerated corrosion procedure. This phase of the experimental investigation is aimed to forecast the structural damage evolution of the main elements of the Turin Exhibition Center once the initiation period is over and the propagation period for corrosion of the reinforcing bar becomes effective. Once some reference level of corrosion will be over, mockups will be tested to compare their structures performances with undamaged reference specimens. Therefore, the evolution of the damage will be directly associated, to the loss of bearing capacity with safety reduction both in service and at ultimate conditions. Rehabilitation techniques as the use of FRCM (Fiber Reinforced Cementitious Matrix) or the use of other thin protective layers and of materials with effects on the cement mortar at the nanoscale will be also employed to explore their effectiveness with deteriorated ferrocement elements. 
R. Ceravolo, G. De Lucia, E. Lenticchia, G. Miraglia, A. Quattrone, F. Tondolo, E. Matta, G. Sammartano, A. Spanò, C. Chiorino, G. Bruschi, P. Faccio, A. Nanni

The experimental analyses will be crucial to define the guidance criteria for the materials conservation and rehabilitation for the $\mathrm{CP}$ of the halls, especially since the halls were built with newly patented construction systems and materials by Nervi himself.

The main aspects considered will concern:

- safety checks with respect to durability with a proposal of upgrade of the traditional systems from inspections methodologies to forecast formula of carbonation diffusion to corrosion structural damage for ferrocement construction improving the awareness of the residual safety level of the structures.

- guidelines for remedial actions and structural rehabilitation; a level of intervention priority will be proposed to check the actual conditions, plan the structural conservation activities and to suggest rehabilitations taking into consideration of the sustainability of interventions basically considering the most advanced and less invasive techniques; with reference also to the results of the experimentation on the effects on durability by additional materials as mentioned in the preceding section.

\subsection{Historical Analysis and Conservation Recommendations}

The conservation plan for the two halls built by Pier Luigi Nervi is an emblematic chance for research studies of structural concrete architectural heritage. The scientific approach implied in this kind of studies reflects the complexity of conservation, restoration and reuse policies requested for great works of modern architecture. This works stream has different objectives:

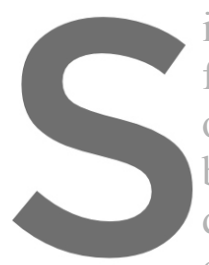
it will closely collabo

for the first step of their of the building, includ

between architecture dense 3D survey, an current Italian and European legislation framewo

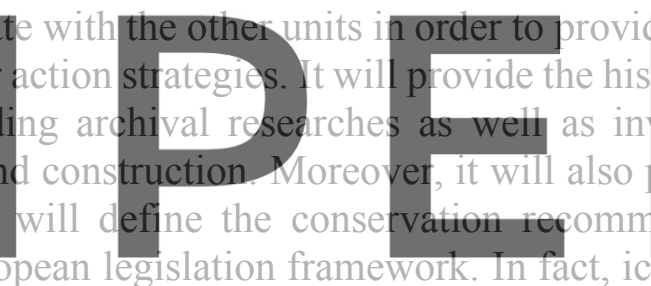

appreciated and internationally recognized, are difficult examples on which to apply and

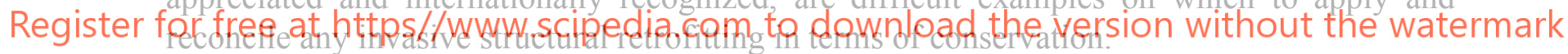

The main challenges connected to this work stream are connected to various kind of criticalities.

In fact, since the building had various owners, and since it has been abandoned for a long time, there is no unified and organized archive related. In particular, archives are located in different cities (Turin, Rome, and Parma), and some documents are in a precarious state of conservation, e.g. the original drawings were realized on tracing papers, which is a very fragile support. Moreover, a precise geometrical survey of the building has never been carried out and maintenance work, that could have caused changes in the interiors of the buildings, has not been adequately documented. The comparative analyses of different historical sources, such as archives, pictures, and videos, can be of great value when analyzing underestimated aspects, such as the use of color. For example some sequences of the film The Italian job, clearly show how the interiors of the building were painted with a cream color (Figure 6), instead of the current bright white. The use of polychromies combined with the use of natural and artificial light sources, introduce new facets in analyzing the work of Nervi that need careful reflections. This is particularly true if we consider the impact of the interventions carried out up to now, even those that were considered not-invasive, such as the operations of ordinary maintenance and some technological updates. 
R. Ceravolo, G. De Lucia, E. Lenticchia, G. Miraglia, A. Quattrone, F. Tondolo, E. Matta, G. Sammartano, A. Spanò, C. Chiorino, G. Bruschi, P. Faccio, A. Nanni
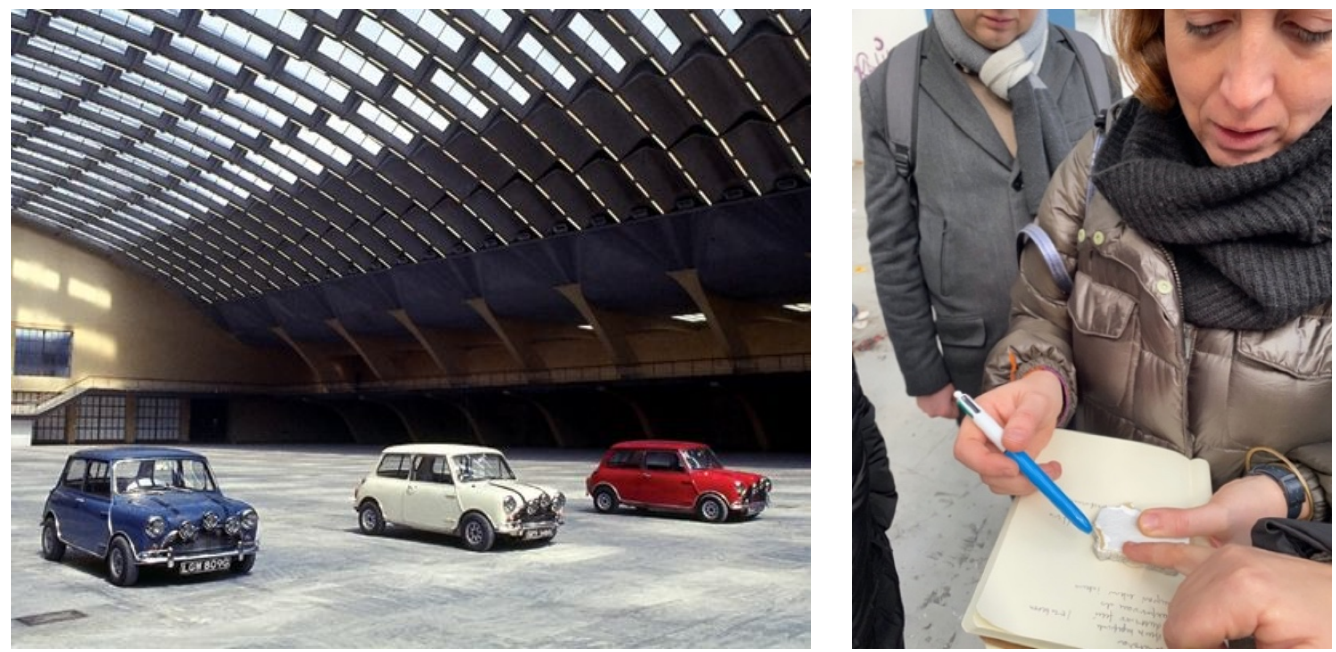

Figure 6: A frame of the movie The Italian Job, 1969, Peter Collinson in which it is possible to appreciate the different polychromies between the vault (painted in grey) and both the slanted pillars and the walls (painted in dark cream color). On the right, a fragment of the plaster of the hall B showings the various layers of coloring.

\section{CONCLUSIONS}

After years of abandonment, the celebrated spatial structures built by Nervi in the Turin Exhibition Center will be the object of an in depth analysis in order to recover them. The grant awarded by the Getty Foundation is a remarkable occasion to establish methodological criteria and guidelines for all structural preservation a concern a) the evaluation of adequate remedial acti he steps to bo undertaken for an ap
of rehabilitation. The restest challenging
ctions to extend it in line with the establish methodolog
issues to be faced in
ated structures and th
new uses foreseen, gical criteria
this respect
and b) the assessment, in compliance with current Italian standards, of the structural safety and reliability

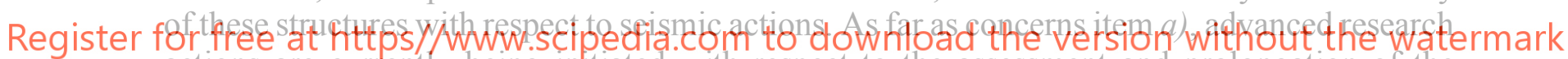
actions are currently being initiated with respect to the assessment and prolongation of the service life of the delicate ferrocement elements of the Pavilions by Nervi. As for item b) a modeling and diagnostic investigations in the dynamic and seismic domain have already been performed. These investigations show some seismic vulnerabilities typical of large span shell and spatial structures that were predominantly conceived to withstand static actions and whose behavior in the dynamic domain was not taken into account in their original conception. Appropriate remedial actions, in terms of strengthening and/or damping interventions, shall be properly defined in the final stage of the reuse project.

Finally, the guidelines will have a broad range applicability, so that it will constitute a reference for possible interventions, not only on Nervi's buildings, but also on the concrete shell architectures which at the time were experimented all over the world.

Acknowledgements. The present work is supported by the Keeping it Modern grant awarded by The Getty Foundation of Los Angeles (USA). The authors would also like to acknowledge the City of Turin, owner of the buildings and active partner of the project, and Società Committenza Piemonte (SCR). 
R. Ceravolo, G. De Lucia, E. Lenticchia, G. Miraglia, A. Quattrone, F. Tondolo, E. Matta, G. Sammartano, A. Spanò, C. Chiorino, G. Bruschi, P. Faccio, A. Nanni

\section{REFERENCES}

[1] K. Normandin and S. Macdonald, "A Colloquium to Advance the Practice of Conserving Modern Heritage: March 6-7, 2013: Meeting Report," The Getty Conservation Institute, Los Angeles, 2013.

[2] T. Prudon, Preservation of Modern Architecture, Hoboken, NJ: John Wiley \& Sons, Inc, 2008.

[3] C. Croft, S. Macdonald and G. Ostergren, Concrete: Case Studies in Conservation Practice, Getty Publications, 2019.

[4] J. Abel, G. Arun and M. Chiorino, "Special Double Issue on Pier Luigi Nervi: Preface by the Guest Editors," Journal of the IASS, vol. 54, no. 176-177, pp. 79-86, April 2013.

[5] C. Chiorino and C. Olmo, Pier Luigi Nervi. Architecture as Challenge, Milano: Silvana Editoriale, 2010.

[6] C. Greco, "The "ferro-cemento" of Pier Luigi Nervi, the new material and the first experimental Building," in Proceedings of the International Symposium of IASS, Padova, 1995.

[7] T. Leslie, "Moving Weights: Nervi's Prefabricated 'Wave Ashlar' Roofs and the Artisanal Cantiere," in Proceedings of the IASS-SLTE 2014 Symposium "Shells, Membranes and Spatial Structures: Footprints", Brasilia, 2014.

[8] C. Greco, Pier Luigi Nervi. Dai primi brevetti al Palazzo delle Esposizioni di Torino 1917-1948, Lucerna: Lucerne Quart Edizioni, 2008.

[9] T. Iori and S. Poretti, "Pier Luigi Nervi: his Construction System for Shell and Spatial Structures," Journal of the IASS, vol. 54, no. 176 \& 177, pp. 117-126, April 2013.

[10] ISC20C, Approaches to the conservation of Twentieth-century cultural heritage Madrid - New Delhi Document, ICOMOS International Committee on Twentieth Century Heritage , 2017.

[11] R. d. L. G. L. E. M. G. Ceravolo, "Seismic structural health monitoring of cultural heritage structures," in Seismic structural health monitoring, Springer Tracts in Civil Engineering, 2019, pp. pp. 51-85.

[12] E. Lenticchia, R. Ceravolo and C. Chiorino, "Damage scenario-driven strategies for the seismic monitoring of XX century spatial structures with application to Pier Luigi Nervi's Turin Exhibition Centre," Engineering Structures, no. 137, pp. 256-267, 2017.

[13] E. Lenticchia, R. Ceravolo and P. Antonaci, "Sensor Placement Strategies for the Seismic Monitoring of Complex Vaulted Structures of the Modern Architectural Heritage," Shock and Vibration, no. art. no. 3739690 DOI: 10.1155/2018/3739690, 2018

[14] P. Nervi, Aesthetics and Technology in Building, The Charles Eliot Norton Lectures ed., Harvard University Press, 1965.

[15] P. L. Nervi, "Palazzo delle Esposizioni - Torino (original projects)," Centro Studi e Archivio della Comunicazione (CSAC) , Parma, 1948-53. 